\title{
PRINSIP INTEGRITAS BERDASARKAN INJIL MATIUS 5:17-48 DAN IMPLEMENTASINYA BAGI PELAYAN TUHAN MASAKINI \\ Manase Gulo \\ manasegulo@sttab.ac.id
}

\section{PENDAHULUAN}

Abstract: $\quad$ Study of Integrity is a very important word, understood and owned by God's servants in the ministry. Today there are many servants of the Lord who carry out the ministry for mere words, but what has been said is not in accordance with daily behavior. As servants of God must have integrity, but in reality today there are still many servants of God who do not yet have integrity. For example, negating some of God's teachings, not living right before God, swearing false (not honest), and not loving the enemy. Therefore it is very important for every servant of God to have integrity. So in this discussion the writer will explain about the integrity of God's servants in service based on Matthew 5: 17-48, which aims to open the understanding of each servant of God about the attitude that must be held by every servant of God in carrying out their ministry.

Keywords: Implementation, Principles, Integrity.

Abstraksi: Study mengenai Integritas adalah suatu kata yang sangat penting, dimengerti dan dimilki oleh hamba Tuhan dalam pelayanan. Pada zaman sekarang ada banyak para pelayan Tuhan menjalankan pelayanan hanya sekedar berkata-kata saja, tetapi apa yang telah dikatakan tidak sesuai dengan perilaku sehari-hari. Sebagai pelayan Tuhan harus berintegritas, namun realitanya sekarang ini masih banyak para pelayan Tuhan yang belum memiliki integritas. Misalnya meniadakan sebagian ajaran Tuhan, tidak hidup benar di hadapan Tuhan, bersumpah palsu (tidak jujur), serta tidak mengasihi musuh. Oleh sebab itu sangatlah penting bagi setiap pelayan Tuhan memiliki integritas. Sehingga dalam pembahasan ini penulis akan memaparkan tentang Integritas pelayan Tuhan dalam pelayanan berdasarkan Matius 5:17-48, yang bertujuan untuk membuka pemahaman setiap pelayan Tuhan mengenai sikap yang harus dimiliki oleh setiap pelayan Tuhan dalam menjalankan tugas pelayanannya.

Kata Kunci: Implementasi, Prinsip, Integritas.

\section{Latar Belakang}

Integritas adalah karakter pribadi yang melekat pada seseorang. Itu adalah keutuhan, kelengkapan, kesempurnaan, kebulatan, kemurnian, kesegaran (budi), kesehatan, kelurusan hati, sifat tidak mencari kepentingan sendiri, ketulusan (tak dapat disuap), kejujuran, kebaikan, kesalehen, sesucian, kemurnian, dan terpercaya". Jadi, saat berbicara tentang integritas tidak pernah lepas dari kepribadian dan karakter seseorang, 
yaitu sifat-sifat seperti: dapat dipercaya, komitmen, tanggung jawab, kejujuran, kebenaran, kesetiaan dan lain sebagainya. ${ }^{1}$

Kebohongan adalah suatu perbuatan yang tidak etis dimilki oleh seorang pelayan Tuhan, tetapi yang seharusnya dimilki oleh seorang pelayan Tuhan adalah moral yang baik. Dalam sebuah pelayanan, moral yang baik sangat diperlukan. Seperti yang tercatat dalam Injil Matius di mana para pemimpin-pemimpin agama Yahudi pada waktu itu mereka berkata-kata dengan perkataan yang lemah-lembut, tetapi dibalik semua itu penuh dengan kemunafikan. Mereka hanya mementingkan adat-istiadat mereka. Mereka sangat berpegang teguh pada aturan adat-istiadat mereka, tetapi mereka sendiri yang melanggarnya. Yesus adalah model integritas yang sempurna. Pujian datang dari orangorang yang mengikuti-Nya, mengenal-Nya, bahkan yang selalu bersama-sama denganNya. "Guru, Engkau adalah seorang yang jujur" (Mrk. 12:14). Pada saat Yesus dihakimi, Pilatus mengakuinya dengan berkata, "Aku tidak mendapati kesalahan apapun pada orang ini”. Integritas menjadi dasar peyanan-Nya, Yesus menjadi tokoh termasyhur karena selama memimpin, tidak didapati kesalahan atau kecurangan dalam diri-Nya. Orang yang memiliki Integritas tinggi akan tenang dalam menjalani hidupnya. ${ }^{2}$

Tuhan Yesus menegur para murid-murid-Nya pada waktu itu, supaya murid-muridNya tidak sama dengan orang-orang Yahudi atau ahli taurat yang penuh kemunafikan. ${ }^{3}$ Matzger mengatakan bahawa, "pelayan Tuhan yang berintegritas dalam pelayanannya tidak ada iklan palsu, semua tindakan selalu benar." ${ }^{4}$ Dengan demikian, sesuai pernyataan di atas maka penulis setuju bahwa orang yang memiliki intergritas adalah orang yang dapat dipercaya yang tidak memiliki dua kepribadian, yang bukan penipu lain di muka lain dihati. Orang yang seperti ini merupakan orang yang punya potensi tinggi karena memiliki sifat yang jujur baik terhadap sesama maupun kepada Tuhan.

Dalam alkitab Allah mengutuk hal berdusta dalam segala bentuknya. "Lidah Dusta" dan "seorang saksi dusta yang menyembur-nyemburkan kebohongan" terdaftar sebagai hal-hal yang menjadi kebencian bagi-Nya (Ams. 6:16-19). ${ }^{5}$ Ada dua macam dampak ketika pelayan Tuhan tidak memiliki integritas yang pertama ialah hasrat-hasrat dan ketakutan-ketakuatan di batin seseorang. Orang yang tidak berdisiplin cepat menyerah kepada perangsang-perangsang dan hawa nafsu. Ia memperturutkan hatinya untuk

\footnotetext{
1 Yosafat, Integritas Pemimpin Pastoral: Menjadi Pemimpin Yang Memadukan Kata-Perbuatan, Iman-Ilmu, Teori-Praktik, Jabatan-Integritas, (Yogyakarta, 2013), 75.

${ }^{2}$ Herwinesastra, Pengaruh Kepemimpinan Kristen Di Era Globalisasi Abad 21..., 53.

${ }^{3}$ Mochtar Lubis, Manusia Indnesia, (Yayasan Idayu, Jakarta, 1978), 23, 24, 39, 40.

${ }^{4}$ Will Metzger, Beritakanlah Kebenaran, (Momentum, 2013), 320.

${ }^{5}$ Jerry White, Kejujuran Moral dan Hati Nurani..., 37.
} 
mendapat harta dan kesenangan tapi menghindari kritik dan kesusahan. Kehidupan macam itu, mendekati kehidupan hewan, bukan manusia. Karena tidak ada tabiat yang kuat, orang cenderung untuk hanya bersaksi perangsang dan mencari jalan yang paling gampang. seseorang memerlukan ketertiban batin yang mengatur hasrat-hasrat seseorang sesuai dengan tujuan pokok dalam kehidupan seseorang. Integritas berarti kemampuan untuk menolak jalan yang tergampang supaya bisa memilih jalan yang terbaik. Pengaruh yang kedua yang dapat menyesatkan seseorang ialah pengaruh lingkungan sosial. Mau tidak mau moralitas seseorang dipengaruhi oleh lingkungan. Bahkan seseorang wajib memperhatikan pandangan orang-orang lain. Namun, seseorang harus mempunyai kesanggupan untuk menolak pandangan-pandangan yang salah. Banyak orang mempunyai moralitas statistic. Keputusan-keputusan mereka ditetukan oleh pandangan banyak orang bukan oleh suara hati mereka sendiri. Suatu perbuatan dianggap benar karena, "segala orang berbuat demikian". Orang yang selalu menyesuaikan diri dengan pandangan yang popular menjadi budak lingkungannya. ${ }^{6}$

Akibat dari alpanya integritas maka para pelayan Tuhan hanya menyampaikan kebenaran firman Tuhan kepada jemaat, tetapi apa yang dikatakan tidak dilakukan atau dengan kata lain meniadakan apa yang sedang diajarkan secara tidak langsung mereka meniadakan ajaran Tuhan karena ajaran yang mereka sampaikan tidak mereka lakukan. Juga dalam perbuatan dan tindakan sehari-hari, tidak benar selalu melenceng dari kebenaran firman Tuhan. Bersumpah palsu demi membela orang yang disenangi. Dari fakta-fakta yang ditemukan maka perlu untuk menuliskan tentang prinsip integritas berdasarkan Injil Matius 5:17-48 dan implementasinya bagi pelayan tuhan masa kini.

\section{Metodologi Penelitian}

Sesuai dengan maksud penelitian, yaitu untuk memahami prinsip integritas berdasarkan Injil Matius 5: 17-48 dan untuk menerapkannya kepada pelayan Tuhan. Maka dibutuhkan metode untuk menjabarkannya. ${ }^{7}$ Metodoologi yang digunakan untuk memperdalam analisa adalah metodologi deskriptif. Metode deskriptif analisis adalah sebuah metode yang memusatkan diri kepada pemecahan masalah yang terjadi saat ini. Menurut Subana dan Suderajat metode deskriptif analisis adalah metode penelitian tentang gejala dan keadaan yang dialami sekarang oleh subjek yang diteliti. ${ }^{8}$ Menurut Edwin

\footnotetext{
${ }^{6}$ Malcolm Brownlee, Pengambilan Keputusan Etis dan Faktor-Faktor Di Dalamn 2011), 134.

${ }^{7}$ Kuncoro Ningrat, Methodologi Penelitian Masyarakat, (Jakarta: Gramedia, 1977), 6.

${ }^{8}$ M. Subana dan Suderajat, Dasar-dasar Penelitian Ilmiah, (Bandung: Pustaka Setia, 2005), 27.
} 
penelitian muncul diakibatkan adanya permasalahan dan adanya keinginan untuk mengetahui jawaban dari permasalahan tersebut. ${ }^{9}$

Dengan metode deskriptif analisis ini akan menyelidiki permasalahan yang sedang terjadi saat ini dan ingin mendapatkan inforamasi tentang penyebab terjadinya permasalahan dan penulis ingin menjelaskan tentang prinsip integritas pelayan Tuhan berdasarkan Injil Matius 5: 17-48 dan aplikasinya. Dalam penelitian ini penulis akan melakukan kajian eksegetikal, menganalisa tulisan-tulisan para teolog dalam mencermati tulisan Matius tersebut.

\section{LATAR BELAKANG INJIL MATIUS}

Dari masa Maleakhi sampai pada permulaan Perjanjian Baru yang ada jarak selama 400 tahun tidak ada seorangpun yang menerima ilham dari Tuhan, oleh sebab itu , masa ini disebut "masa kegelapan" di samping itu pengaruh kebuadayaan Yunani semakin kuat sehingga timbul penganiayaan tehadap orang Yahudi. ${ }^{10}$

Pada zaman kerajaan Siria, dalam peperangan antara Siria dan Mesir, Antiochus merampas Palestina dari Ptolomeus, raja Mesir, yang semakin memberatkan ialah bahwa raja ini sangat dendam terhadap orang Yahudi. Dengan sekuat tenaga ia berusaha memusnahkan agama mereka. Kota Yerusalem dibinasakan dan bait Allah dicemarkan dengan persembahan seekor babi betina di atas mezbah Tuhan, dan mereka melarang orang Yahudi untuk beribadah di Bait Allah, mereka tidak diizinkan untuk bersunat, dan jika mereka mendapatkan gulungan firman Tuhan dari orang Yahudi maka mereka akan dimusnahkan bagi orang yang tertangkap yang membawa gulungan firman Tuhan. Selain itu, beribu-ribu keluarga Yahudi dijual sebagai budak dan mereka menyiksa bangsa Yahudi untuk melepaskan diri dari agamanya atau kepercayaannya sendiri. ${ }^{11}$

Selanjutnya pada waktu itu kebudayaan Yunani sudah mulai masuk ke tanah Yudea dan membahayakan kemurnian agama orang-orang Yahudi, ketika seluruh Asia kecil diserbu oleh Alexander Agung, maka pengaruh Yunani menjadi semakin kuat, dan timbullah aliran agama yang sinkretistis yang pro Yunani. Antiokus dipukul mundur oleh tentara Romawi dan dipaksa untuk membayar hutang perang. Akhirnya Antiokus menggunakan kekerasan dengan memaksa orang-orang Yahudi untuk membayar pajak yang tinggi supaya dia dapat membayar hutang perangnya itu, dan bukan hanya pajak saja 2008,144

${ }^{9}$ Mustafa Edwin dan Hardius, Proses Penelitian Kuantitatif, (Jakarta: Lembaga Penerbit FEUI,

${ }^{10}$ Adima Chapman, Pengantar Perjanjian Baru, (Bandung: Sahabat Kalam Hidup II, 2014), 4.

${ }^{11}$ Ibid., 5. 
yang mereka bayar melainkan ekonomi merekapun tertekan ke bawah. Oleh sebab itu, timbullah rasa tidak puas dikalangan rakyat Yahudi. Selain dari hutang dan ekonomi muncullah ajaran baru atau golongan-golongan dari para, orang farisi ${ }^{12}$, orang Herodian ${ }^{13}$ dan orang zelot ${ }^{14}$, dan ahli taurat. ${ }^{15}$

Profesi kelompok ini lebih berkembang ketika orang Yahudi harus menghadapi pengaruh yang sangat kuat dari Hellenisme. Ketika itu, orang-orang Yahudi ingin mempertahankan keleluasan aturan-aturan yang berkaitan dengan hukum Taurat, sementara pengajaran para imam tidak lagi memadai. Ahli Taurat ini memiliki keahlian dalam memelihara tradisi dan dalam menafsirkan serta aplikasi dari isi Alkitab, mereka juga disebut sebagai orang berhikmat, atau guru hukum Taurat dan tuan. Hukum Taurat itu diberlakukan dalam semua area kehidupan manusia, sehingga mereka mengatur hal-hal yang mendetail berkaitan dengan kehidupan pribadi, kehidupan domestic, kehidupan social, sampai pada yang bersifat umum. Misalnya, seberapa jauh seseorang harus berjalan pada hari sabat, dan sebagainya. Aturan-aturan yang sedemikian banyak harus dipelajari semuanya seumur hidup, akibatnya menjadi beban bagi setiap orang. ${ }^{16}$

${ }^{12}$ Nama Farisi berasal berasal dari bahasa Ibrani Peruschim, artinya: orang yang memisahkan diri. Nama ini pertama kali dikenakan kepada mereka oleh orang di luar kelompok itu, sebab mereka menarik diri dari lingkungan dengan maksud membentuk satu "komunikasi yang kudus" milik Allah, dan menghindari kontak dengan lingkungan yang tidak tahir. Menurut Flavias, kaum Farisi adalah satu kelompok orang Yahudi yang memiliki reputasi yang luarbiasa dalam memberikan kenyamanan bagi negeri mereka dengan cara mentaati aturan agama dan juga sebagian kelompok yang memberikan penafsiran yang tepat mengenai hukum taurat. Awal mula munculnya kelompok Farisi ini adalah pada zaman Makabe. Pada waktu itu dibutuhkan upaya untuk mempertahankan iman orang Yahudi terhadap pengaruh Hellenisasi. Dalam 1 Makabe 2:42, disebutkan tentang suatu kelompok kesalehan atau suatu kelompok yang gagah berani dalam menundukkan diri kepada Hukum Taurat. Mereka sangat mendukung pemberontakan Makabe melawan penindasan keagamaan yang dilakukan oleh Antiokhus IV Epifanes (Lih.: Samuel Benyamin Hakh, Perjanjian Baru, (Bandung: Bina Media Informasi, 2010), 33)

${ }^{13}$ Herodian adalah satu kelompok partai politik yang mendukung pemerintahan Herodes dan keturunannya termasuk Roma. Dengan demikian, kedudukan Herodes dapat dipertahankan. Dalam kenyataannya, Mereka adalah kelompok minoritas di antara mayoritas orang Yahudi yang menentang pemerintah Herodes. Dalam Injil-Injil (Mat. 22:16; Mrk. 3:6; 8:15; 12:13) bersama orang Farisi bersekongkol untuk membunuh Yesus (Mrk. 3:6). Sebab, memang Herodes Antipas yang telah memenggal kepada Yohanes Pembabtis (Mrk. 6:16) mau bekerja sama dengan kelompok Farisi untuk menentang Yesus (Lih.: Albert A. Bell, Exploring The New Tetament World, (Nashville: Thomas Nelson Publishers, 1998), 44)

${ }^{14}$ Kelompok Zelot Mereka adalah kaum nasionalis yang fantik yang ingin melepaskan diri dari penjajahan Romawi. Mereka percaya bahwa Allah adalah satu-satunya yang memimpin mereka. Oleh Karena itu mereka sering melakukan pemberontakan melawan pemerintahan Romawi (Lihat Kis. 5:37; Mark. 12:14) (Lih. :Adina Chapman, Pengantar Perjanjian Baru, (Bandung: Kalam Hidup, 2014), 4).

15 Ola Tulluan, Introduksi Perjanjian Baru, (Malang: Yayasan Persekutuan Pekabaran Injil Indonesia, YPPI, 1999), 2. Bdg. Ahli Taurat mulai muncul setelah pembuangan dari Babel. Kelompok ini muncul pada masa Ezra. Ia, seorang imam tetapi juga seorang ahli kitab (Ezra 7:11). Ia tetap melaksanakan tugas imam, tetapi ia juga mengumpulkan kelompok orang yang bertugas untuk menyalin tulisan-tulisan suci. Atas persetujuan dari raja Persia, Ezra mengharuskan komunitas yang baru kembali dari Babel itu untuk melaksanakan Taurat. Itulah sebabnya ia dicirikan sebagai "seorang rabi yang ahli dalam Kitab Musa yang Tuhan Allah Israel, telah berikan (Ezr. 7:6) (Lih.: H. I. Hester, The Heart of The New Testament, (Nashville, Tennesse: Bradmen Press, 2001), 63)

${ }^{16}$ Ibid.,64. 


\section{Latar Belakang Teks_Matius 5:17-48}

Peristiwa yang terjadi pada waktu Tuhan Yesus mengajajar dan meluruskan ajaranajaran para ahli Taurat atau orang-orang Farisi yang merasa diri lebih suci. Orang-orang Farisi pada waktu itu sangat mempertahankan adat-istiadat mereka, serta sangat berpegang pada hukum taurat. Hal itu membuat Yesus ingin meluruskan ajaran-ajaran ahli Taurat pada saat itu. Menurut Yesus sendiri bahwa semua yang diterapkan para ahli Taurat pada waktu itu hanya bertujuan agar orang lain menilai mereka bahwa mereka adalah orangorang yang taat, suci, dan paling benar. Mereka yang menetapkan aturan, dan mereka juga yang melanggarnya. Misalnya, Para ahli taurat pada masa itu menganggap hal biasa ketika mengucapkan kata-kata yang mengandung unsur sumpah. Sedangkan Kata sumpah berhubungan dengan kaul. Bila seseorang berjanji, maka ia hanya membenarkan bahwa ia mau atau melakukan sesuatu, dan masih banyak contoh lain yang bertentangan dengan ajaran Tuhan Yesus antara ajaran ahli taurat dan orang-orang Farisi pada waktu itu.

Biasanya orang yang bersumpah menyerukan hukuman (Dewa, Allah) seandainya ia tidak melaksankan apa yang dijanjikan atau dinyatakannya secara meriah. Bila seseorang bersumpah, maka ia menyatakan secara meriah bahwa memang sesuatu yang benar. Dalam konteks ini Yesus sendiri sebernarnya tidak bersikap anti sumpah. Tetapi Yesus tidak dapat menerima usaha membeda-bedakan berbagai rumusan sumpah yang dipakai orang-orang Yahudi. Ada sejumlah guru Yahudi yang mengajarkan bahwa sumpah tidak mengikat bila dibuat demi langit dan di bumi. Tetapi Yesus mengajar bahwa entah nama Allah disebut entah tidak disebut manusia yang bersumpah tetap berurusan dengan Allah. Langit dipandang sebagai takhta Allah, yaitu tempat yang dipakai Allah untuk memerintah dunia. Allah digambarkan sebagai Raja, Ia duduk di atas takhta sedangkan kaki-Nya mengaso di atas sebuah tumpuan atau injakan khusus (Yesaya 66:1; 1 Taw. 28:2 Intinya adalah, konteks pada saat itu adalah Tuhan Yesus ingin meluruskan ajaran-ajaran orang Farisi pada waktu itu.). ${ }^{17}$

\section{KAJIAN EKSEGETIS INJI MATIUS 5:17-48}

Dalam pelayanan manapun, yang terpenting dimiliki adalah "Integritas" maka dari itu Tuhan Yesus sendiri menghimbau agar setiap para pelayan Tuhan harus memiliki "Integritas" dalam pelayanan. Setiap pelayan Tuhan mampu mempertahankan jati dirinya

${ }^{17}$ Stefan Leks, Tafsiran Injil Matius, (Anggota Ikapi, 2007), 160. 
sebagai pelayan Tuhan, jangan seperti orang-orang Farisi pada waktu itu yang penuh kemunafikan, yang dari luar kelihatan suci sedangkan dalamnya penuh kebusukkan. Dalam hal ini penulis akan mengeksegese kata-kata penting yang mendapatkan kajian yang mendalam sehingga dapat memahami "Integritas Pelayan Tuhan dalam Pelayanan" yang terdapat dalam Injil Matius 5:17-48 adalah sebagai berikut.

\section{Tidak "Meniadakan" ( ayat 17-19)}

Sebagai hamba Tuhan yang memilik integritas, yaitu tidak meniadakan perintah Tuhan. Kata "Meniadakan" dalam bahasa aslinya (Yunani) memakai kata $\kappa \alpha \tau \alpha \lambda \hat{v} \sigma \alpha \iota$

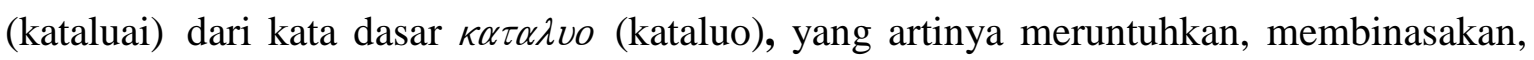
membatalkan, melenyapkan. ${ }^{18}$ Kata ini memakai kasus verb infinitive aorist active ${ }^{19}$. Yang artinya infinitive kata kerja aorist aktif. Sedangkan dalam KBBI kata 'meniadakan' diartikan memandang (menyatakan) tidak ada, mengingkari, menentang, dan lain

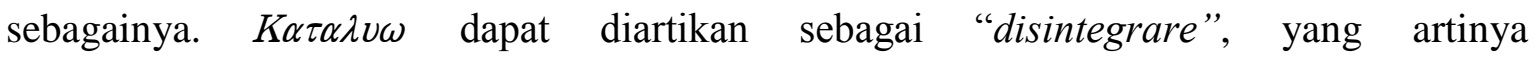
mengahancurkan, 'To demolish', yang artinya merobohkan. K $\alpha \tau \alpha \lambda \nu \omega$ juga diartikan 'to dissolve' memecahkan, 'to destroy' menghancurkan. ${ }^{20}$ Dalam terjemahan lain memakai kata 'to abolish" yang artinya 'menghapuskan. ${ }^{21}$ Jadi, artinya bahwa pelayan Tuhan yang berintegritas yaitu harus mampu mempertahankan ajaran-ajaran yang dari pada Tuhan, bukan sebaliknya meniadakan. Yesus datang ke dunia untuk menjadi pelayan Allah dan juga pelayan manusia, dengan satu misi yaitu bukan untuk menghancurkan, meniadakan hukum Taurat, melainkan untuk menggenapi hukum Tuhan tersebut. Dalam teks ini sangat jelas bahwa Tuhan Yesus datang bukan untuk meniadakan hukum Taurat, melainkan untuk melakukan apa yang dikatakan hukum Taurat itu. ${ }^{22}$

Dalam Versi FAYH menuliskan: "Janganlah salah paham mengenai kedatangan$\mathrm{Ku}$. Aku datang bukan untuk menghapuskan Hukum Musa dan pengajaran para nabi, melainkan untuk menggenapkannya. ${ }^{23}$ Dalam Versi BIS menuliskan bahwa Tuhan Yesus datang bukan untuk 'menghapuskan', tetapi untuk menunjukkan arti yang sesungguhnya. ${ }^{24}$ Dalam NKJV menggunakan kata 'to destroy” yang artinya Tuhan Yesus datang bukan

\footnotetext{
${ }^{18}$ Hasan Susanto, Perjanjian Baru Interlinear Yunani Indonesia dan Konkordansi Perjanjian Baru, (Lembaga Alkitab Indonesia, 2004), 435.

${ }^{19}$ Bibleworks, Pukul 09.00.

20 Harord K. Moulton, The Analytical Greek Lexicon Revised, (America: The Zondervan Corporation Grand Rapids, 1977), 218.

${ }^{21}$ Kurt Aland, Synopsis of The Four Gospels, (America: United Bible Societies, 1985), 167. 1901), 40

22 James Strong, Strongs Exhaustive Concordance of the Bible, (American: World Bible Publishers,

${ }^{23}$ Sabda, (I_FAYH), Mat. 5:17

${ }^{24}$ Sabda, (BIS), Mat. 5:17
} 
untuk menghancurkan tetapi 'to fulfill' Tuhan Yesus datang untuk memenuhi hukum taurat tersebut. ${ }^{25}$ Sedangkan dalam versi BSD menuliskan "Jangan mengira Aku datang untuk mengajar kalian supaya tidak lagi menaati hukum Musa dan ajaran nabi-nabi. Aku datang bukan untuk menghapuskan, tetapi untuk menunjukkan arti yang sesungguhnya dari hukum-hukum dan ajaran-ajaran itu. ${ }^{26}$

Terjemahan yang paling baik adalah bahwa Yesus mau merealisasikan perintahperintah itu secara penuh. Kata Yunani yang dipakai di sini ialah $\pi \lambda \epsilon \rho o o$ (pleroo), yang berarti bahwa Tuhan Yesus mau melaksanakan dan menjelaskan perintah-perintah Allah dalam "ukuran penuh" ("pleroo" berarti penuh), dan mau menjelaskan arti yang paling dalam dari perintah-perintah Tuhan itu. ${ }^{27}$ Barclay menjelaskan dalam bukunya bahwa:

Yesus datang untuk membawa makna yang sebenarnya dari hukum Taurat itu. Prinsip dasar yang pokok itu ialah, bahwa di dalam segala hal manusia harus mencari kehendak Allah, dan bahwa kalau manusia tersebut menemukannya, ia harus mempersembahkan seluruh hidupnya untuk mentaati kehendak Allah itu. ${ }^{28}$

Dengan demikian penulis setuju dengan pernyataan tersebut bahwa Tuhan Yesus datang untuk membawa makna yang sebanarnya dari hukum Taurat tersebut. Tuhan Yesus menunjukkan integritas-Nya dalam pelalayanan selama melayani di dunia, tidak meniadakan satu iotapun dari hukum taurat tersebut. Demiakian juga sebagai palayan Tuhan yang berintegritas tidak boleh meniadakan ajaran-ajaran Tuhan yang telah diterima lewat alkitab.

Dalam ayat 19 Tuhan Yesus mengatakan bahwa hukum yang terkecilpun dari hukum taurat tidak boleh ditiadakan. Jangan kita berpikir bahwa Yesus membedakan hukum-hukum yang "Penting" dan yang "tidak penting”. Beberapa ahli Perjanjian Baru berpendapat bahwa "hukum yang terkecil" di sini berarti "hukum yang pendek", seperti misalnya hukum-hukum di dekalog (kesepuluh hukum). Segenap hukum Taurat dari Perjanjian Lama tetapi diakui oleh Yesus, tetapi apa yang Ia akui ialah arti yang dalam dari hukum Taurat itu. Siapa yang melakukan dan mengajarkan perintah-perintah hukum Taurat, akan menduduki tempat tertinggi dalam kerajaan sorga ("Sorga" berarti Tuhan), tetapi yang mencoret apa-apa dalam hukum Taurat itu akan menduduki tempat yang rendah dalam kerajaan Tuhan. Jadi, dalam kerajaan Tuhan ada tingkat-tingkat. Mungkin

\footnotetext{
${ }^{25}$ Sabda, (NKJV), Mat. 5:17

${ }^{26}$ Sabda, (BSD), Mat. 5:17

${ }^{27}$ Kittel, Theological Dictionary of the N. T (pada perkatan "nomos" dan pada perkataan "pleroo")

${ }^{28}$ William Barclay, Pemahaman Alkitab Setiap Hari, (PT BPK Gunung Mulia, 2003), 219.
} 
juga bahwa ada penafsir ahli Perjanjian Baru benar adanya bahwa "tempat yang terendah dalam kerajaan Sorga adalah istilah untuk tempat di luar kerajaan Tuhan". ${ }^{29}$

\section{Hidup Benar (ayat 20-25)}

Kata 'Benar' dalam bahasa aslinnya memakai kata $\delta l \kappa \alpha l o \sigma v v \eta$ (dikaiosune), yang artinya kebenaran, dengan adil. Kata ini memakai kasus noun nominative feminine singular. ${ }^{30}$ yang artinya kata benda yang nominative tunggal feminim. Dalam terjemahan lain kata $\delta \iota \kappa \alpha \iota \sigma \sigma v v \eta$, menggunakan istilah 'uprightness', yang artinya 'tegak lurus', 'legally justice', yang artinya 'menutut hukum keadilan'. ${ }^{31}$ Sedangkan dalam KBBI 'Benar adalah sesuai sebagaimana adanya (seharusnya), tidak berat sebelah, dan dapat dipercaya (cocok dengan keadaan yang sesungguhnya); tidak bohong. ${ }^{32}$ Dalam terjemahan lain kata

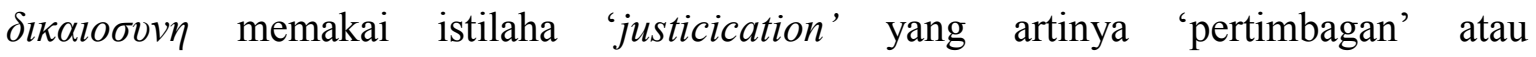
'righteousness' yang artinya 'kebajikan'. ${ }^{33}$ Jadi apabila tidak melakukan pertimbangan dalam melakukan hal, maka tindakan yang dilakukan selalu bertentangan dengan Firman Tuhan, sehingga dampaknya tidak menghasilkan kebajikan yang berbeda dengan orang Farisi, dan ahli Taurat.

Hidup benar yang diinginkan oleh Tuhan Yesus adalah hidup takut akan Tuhan, menjauhi larangan-Nya. Ada banyak larangan-larangan Tuhan Yesus, seperti: membunuh, menganggap orang lain kafir, dan berzinah. Hal tersebut adalah kekejian di mata Tuhan. Siapa yang melanggarnya akan mendapat hukuman dari Tuhan. Ketiga perbuatan tersebut berhubungan dengan hukum Tuhan. ketika Tuhan sudah melarang, siapa yang melanggar adalah orang tersebut seorang pembuat dosa. Upah dosa adalah maut, yaitu menuju pada kebinasaan dan kematian kekal. ${ }^{34}$ Jadi, pelayan Tuhan yang berintegritas mampu menjali hidup dengan benar di hadapan Tuhan, dengan kata lain tidak melanggar perintah yang Tuhan tetapkan.

\section{Tidak "Bersumpah Palsu” (ayat 33-37)}

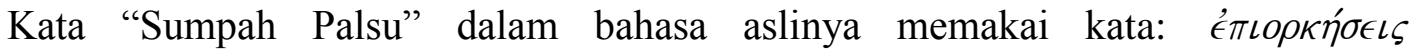
(epiorkeseis) dari kata dasar $\varepsilon \pi \imath о \rho \kappa \varepsilon \omega ~(e p i o r k e o)$, yang artinya: kesaksian palsu, sumpah

\footnotetext{
${ }^{29}$ J. J. de Heer, Tafsiran Alkitab Injil Matius, (PT BPK Gunung Mulia, 2003), 81.

${ }^{30}$ Hasan Susanto, Perjanjian Baru Interlinear Yunani Indonesia dan Konkordansi Perjanjian Baru..., 213.

${ }^{31}$ Barbara Friberg, Analytical Lexicon of The Greek New Testament, (Nashvile: Nelson 1985), 49.

${ }^{32}$ Dendy Sugono, Kamus Besar Bahasa Indonesi Pusat Bahasa, (Jakarta: PT Gramedia Pustaka Utama, 2011), 167.

${ }^{33}$ James. Strongs Exhaustive Concordance of the Bible, (American: World Bible Publishers, 1901), 23.

${ }^{34}$ A. Simanjuntak, Tafsiran Alkitab Masa Kini 3...,73.
} 
palsu. Kata ini memakai kasus verb indicative future active person singular, artinya, yaitu suatu kegiatan yang dikerjakan ke depan oleh seseorang yang secara aktif. ${ }^{35}$ Dalam terjemahan lain kata $\varepsilon \pi \iota \rho \kappa \varepsilon \omega$, memakai istilah 'swear falsely' yang artinya 'sumpah yang dengan licik'. ${ }^{36}$ Jadi orang yang 'bersumpah palsu' sama artinya orang yang penuh dengan kelicikan. Dalam terjemahan lain kata $\varepsilon \pi \iota \rho \kappa \varepsilon \omega$, menggunakan istilah 'Commit Perjury', yang artinya 'melakukan sumpah palsu'. 37

Perjanjian Lama yang tercatat dalam Imamat 19:12: “janganlah kamu bersumpah dusta demi nama-Ku, supaya engkau jangan melanggar kekudusan nama Allah-mu. Pada masa Tuhan Yesus, sudah menjadi suatu penyakit orang Yahudi untuk selalu menguatkan ucapannya dengan sumpah. Sebab orang Yahudi takut untuk memakai nama Allah, maka mereka seringkali dalam sumpah mengganti nama Allah dengan kata lain, misalnya: demi taurat, demi Yerusalem, demi kepalamu. ${ }^{38}$

Tuhan Yesus mengajarkan orang percaya supaya tidak sembarang bersumpah, apalagi ditambah dusta, itu sangat jelas Tuhan Yesus tidak menghendaki hal itu. Alkitab pun menyatakan: "Jangan menyebut nama Tuhan, Allahmu, dengan sembarangan, sebab Tuhan akan memandang bersalah orang yang menyebut nama-Nya dengan sembaranjgan”. (Kel. 20:7). Di balik sumpah itu terdapat hal yang penting. Jika nama Allah dipakai, maka Allah menjadi pihak yang teribat di dalam sumpah itu. Yesus memberitahukan kebenaran kekal yang besar. $^{39}$

Dalam ayat 37 ini Tuhan Yesus ingin menegaskan bahwa dalam berkata-kata harus didasari dengan kebenaran. "Jika ya, hendaklah kamu katakan: ya, jika tidak, hendaklah kamu katakan: tidak. Apa yang lebih dari pada itu berasal dari si jahat". kata 'Ya' dalam bahsa aslinya memakai kata 'vol' yang artinya sungguh, tentu saja. Diterjemahkan secara harfiah dari bahasa Yunani yang berarti "tetapi biarlah perkataan-mu ya, ya atau tidak, tidak".

Dalam Versi BSD mengatakan Karena itu, katakan saja, 'Ya,' tanpa memakai sumpah, atau, 'Tidak,' tanpa memakai sumpah. Jika kautambahkan kata-kata lain pada pernyataanmu itu, tambahan itu berasal dari si Iblis". ${ }^{40}$ Dalam FAYH Katakan saja 'Ya'

\footnotetext{
Baru..., 22.

${ }^{35}$ Hasan Susanto, Perjanjian Baru Interlinear Yunani Indonesia dan Konkordansi Perjanjian

36 Jhanes E. Louw, Greek-English Lexicon of The New Testament, (New York: United Bible Societies, 1989), 75

${ }^{37}$ Barbara Friberg, Analytical Lexicon of The Greek New Testament, (Nashvile: Nelson 1985), 75.

${ }^{38}$ J. J. De Heer, Tafsiran Alkitab Injil Matius, (PT BPK Gunung Mulia, 2011),..86

${ }^{39}$ Willianm Barclay, Pemahaman Alkitab Setiap Hari..., 267.

${ }^{40}$ Sabda, (BSD), Mat. 5:37.
} 
atau 'Tidak'. Itu sudah cukup. Meneguhkan janji dengan sumpah menunjukkan bahwa ada sesuatu yang tidak beres. ${ }^{41}$ Sedangkan dalam NKJV menggunakan kata 'Yes be 'Yes,' and your 'No,' 'No.' For whatever is more than these is from the evil one. Artinya bahwa apa pun yang lebih dari pada itu, berasal dari Iblis. ${ }^{42}$

Ayat ini memiliki kesamaan dengan Yakobus 5:12. Gereja purba menafsirkan ayat ini dengan arti "setiap kali kamu menjawab ya, harus kamu katakan dengan ya saja, begitu juga jika tidak, cukup dengan tidak saja”. Ungkapan itu antara lain telah diterjemahkan bergini: 'kamu harus mengatakan 'ya' jika maksudmu 'ya' dan 'tidak' jika maksudmu 'tidak'. Perkatan ini mengandung artian bahwa jika seseorang mengatakan sesuatu dengan seadanya, tanpa mengandung unsur kebohongan, supaya orang lain lebih percaya terhadap apa yang disampaikan. sebagai hamba Tuhan harus memiliki konsep seperti ini, berkata seadanya, tanpa ada penipuan, atau dengan kata lain bahwa perkataan 'Ya' menunjukkan sikap yang jujur tanpa kemunafikan. ${ }^{43}$

Sebenarnya maksud Tuhan di dalam ayat ini adalah agar orang percaya memiliki integritas dalam kejujuran. "Jika kita mengatakan yang benar maka sumpah itu sama sekali tidak perlu. Sebab tiap-tiap perkatan diucapkan di hadirat Allah mempunyai kekuatan sebagai sumpah."44 Jujur artinya tidak ada unsur memalsukan sesuatu hal. Kata Jujur dalam Kamus Besar Bahasa Indonesis adalah lurus hati, tidak berbohong, berkata apa adanya, tidak curang. ${ }^{45}$ Sangat ditekankan di sisni adalah sebagai pelayan Tuhan tidak boleh memiliki dua kepribadian, yang artinya adalah beda di mulut beda juga di hati. sebagai hamba Tuhan harus jujur dalam segala segi tidak boleh berpura-pura baik pada hal tidak baik.

\section{Mengasihi Musuh (ayat 44)}

Kata "Mengasihi" dalam Kamus Besar Bahasa Indonesi diartikakan menaruh belas kasihan. ${ }^{46}$ Sedangkan dalam bahasa aslinya memakai kata $\alpha \dot{\alpha} \alpha \pi \hat{\alpha} \tau \epsilon$ (agapate), dari kata dasar $\alpha \gamma \alpha \pi \alpha \omega$ (agapao) yang artinya manaruh kasih, mecintai, menyukai, dan merindukan.

\footnotetext{
${ }^{41}$ Sabda, (i_FAYH), Mat. 5:37.

${ }^{42}$ Sabda, (NJKV), Mat. 5:37.

${ }^{43}$ J. 1. Ch. Abineno, Khotbah Di Bukit Catatan-Catatan Matius 5-7, ( Jakarta: BPK Gunung Mulia, 2009), 163.

44 J. Verkuyl, Khootbat di Bukit...,53.

${ }^{45}$ Dendy Sugono, Kamus Besar Bahasa Indonesia Pusat Bahasa, (PT. Gramedia Pustaka Utama Jakarta, 2011), 591.

${ }^{46}$ Daniel Haryono, Kamus Besar Bahasa Indonesi Edisi Baru, (Jakarta: PT Muliapurna Jayaterbit, 2012), 421.
} 
Kata ini memakai kasus, verb imperative present active person plural. ${ }^{47}$ Yang artinya bahwa suatu kegiatan yang harus dilakukan (mendesak), tidak bisa ditolak, yang dilakukan lebih dari satu orang (jamak). Dalam terjemahan lain kata $\alpha \dot{\alpha} \alpha \pi \hat{\alpha} \tau \epsilon$, memakai istilah 'to treat with affection', yang artinya 'bermufakat dengan kasih sayang', 'to caress' yang artinya 'untuk membelai', ${ }^{48}$

Dalam 1 Yoh. 7:4: "Saudara-saudaraku yang kekasih, marilah kita saling mengasihi, sebab kasih itu berasal dari Allah; dan setiap orang yang mengasihi, lahir dari Allah dan mengenal Allah." 49 Mengasihi adalah suatu kata yang bentuknya bersifat perintah dan memiliki unsur keharusan tidak boleh ditolak. Di dalam Mrk 12:33a: "Memang mengasihi Dia dengan segenap hati dan dengan segenap pengertian dan dengan segenap kekuatan, dan juga mengasihi sesama manusia seperti diri sendiri adalah jauh lebih utama dari pada semua korban bakaran dan korban sembelihan." ${ }^{50}$ Kasih menjadi tujuan hidup setiap orang percaya, maka setiap orang menjadikan kasih sebagai cara hidup, hal itu sangat mendasar dan cara yang bertanggung jawab dalam segala aspek kehidupan setiap orang. Kasih Tuhan adalah soal kedisiplinan dalam relasi. Jadi kasih kristiani tidak berbicara banyak mengenai apa yang dirasakan tetapi apa yang dilakukan bagi orang lain. $^{51}$

Hal yang tetap dituntut oleh Yesus ialah kasih. Tuhan Yesus mengatakan: "Kasihilah musuhmu". Musuh di sini berarti semua macam musuh, entah orang kafir diluar Israel, entah golongan di dalam Israel yang memusuhi golongan-golongan yang lain, entah musuh-musuh pribadi. Baiklah kita insaf bahwa "kasih" terhadap musuh bukan terdiri atas perasaan hati saja, melainkan terdiri atas kemauan dan perbuatan. Kasih adalah undang-undang dasar kerajaan Allah. Mengasihi setiap orang adalah "hukum yang baru" yang dinyatakan oleh Yesus dengan cara lebih jelas dari pada Perjanjian Lama. Betapa lega hati kita, apabila kita mengasihi musuh-musuh kita! Ketegaran dan kepahitan hilang dari hati kita, dan sikap kita menjadi sikap yang membangun. Yesus mengatakan: "berdolah bagi mereka yang menganiaya kamu" (Mat. 5:44). Mendoakan musuh-musuh kita adalah suatu alat yang kuat untuk menghilangkan kebencian dari dalam hati kita. ${ }^{52}$

\footnotetext{
47 Hasan Susanto, Perjanjian Baru Interlinear Yunani Indonesia dan Konkordansi Perjanjian Baru..., 24

${ }^{48}$ Robert Scott, Greek-English Lexicon, (Leipzig, 1858), 2.

${ }^{49}$ Bibleworks, Pukul 21.15 WIB.

${ }^{50}$ Lembaga Alkitab Indonesia

${ }^{51}$ John M. Drescher, Melakukan Buah Roh, (Jakarta: Gunung Mulia, 2009), 55.

52 J. J De Heer, Tafsiran Alkitab Injil Matius...,91.
} 
Mengasihi sesama manusia merupaka perintah diberikan Yesus kepada orang percaya untuk tetap hidup dengan penuh kasih. Kasih yang harus dimilik oleh umat kristiani ialah kasih agape, sebab kasih agape ialah kasih yang diajarkan oleh Tuhan Yesus sendiri dimana Tuhan Yesus membiarkan sebuah kasih kepada semua orang percaya tanpa pamrih, tanpa batas. Sekarang kita telah melihat maksud Yesus dengan perintah-Nya agar kita memiliki kasih kristiani. Mengapa Yesus menghendaki agar orang percaya memiliki kasih, agar dengan kasih itu manusia menjadi segambar dengan Allah. Yesus menunjukkan tindakan Allah di dunia ini. Dan tindakannya itu adalah kebajikan yang tak mengenal batas. Allah menerbitkan matahari-Nya untuk menyinari orang yang baik dan orang yang jahat. Yesus menginginkan supaya setiap orang yang percaya kepada-Nya memiliki kasih seperti Allah sehingga setiap orang percaya menjadi "anak-anak Bapa yang di Sorga. ${ }^{53}$

\section{IMPLEMENTASI PRINSIP INTEGRITAS BERDASARKAN INJIL MATIUS 5:17-48 BAGI PELAYAN TUHAN MASA KINI}

Berdasarkan kajian eksegetikal di atas, maka ada beberapa prinsip integritas yang akan dipaparkan bagi para pelayan Tuhan.

\section{Pelayan Tuhan Tidak Meniadakan Ajaran Tuhan}

Sebagai pelayan Tuhan, yang lebih utama adalah tidak meniadakan ajaran-ajaran Tuhan. ketika seorang pelayan Tuhan meniadakan ajaran Tuhan berarti pelayan Tuhan sedang mengajarkan, memberikan ajaran sesat kepada jamaat yang sedang dilayani. Meniadakan sama halnya tidak konsisten terhadap aturan dan ketetapan-keteapan Allah. ${ }^{54}$

Konsisten adalah hal yang harus dimiliki oleh setiap pelayan Tuhan. Dalam pelayanan sebagai pelayan Tuhan, kekonsistenan sangat diperlukan. Kekonsistenan mencakup banyak hal misalnya, konsisten dalam pengajaran, berpegang teguh pada kebenaran, tidak mudah goyah, memiliki pendirian yang kokoh, serta taat. Artinya bahwa setiap orang yang memiliki pola hidup yang konsisten tidak pernah takut ancaman, selalu berpegang teguh pada kebenaran. Pelayan Tuhan yang berhasil mereka yang aktif menaati semua amanat Tuhan Yesus lewat firman-Nya, mereka hidup berdasarkan apa yang Yesus katakan dan harus lakukan. Itu sebabnya, Allah menggenapi janji-janji-Nya kepada mereka secara pribadi dan melalui pelayanan mereka. ${ }^{55}$

\footnotetext{
${ }^{53}$ William Barclay, Pemahaman Alkitab Setiap Hari..., 297.

${ }^{54}$ Caleb Tong, Kepemimpinan dan Pembinaan Warga Gereja, (Jakarta: Sinar Harapan, 1998), 182.

${ }^{55}$ Mike Shipman, Kepemimpinan Kerasulan, (Bandung: Penerbit Dian Cipta, 2017), 75.
} 
Dalam sebuah pelayan berhasilnya pelayanan tergantung kepada para pelayannya. Tuhan Yesus adalah contoh pelayan yang memiliki sikap konsisten penuh, di mana Ia datang ke dunia untuk mengajar, apa yang Ia ajarkan Ia juga melakukannya. Artinya bahwa apa yang diucapkan Tuhan Yesus itu juga yang Ia lakukan atau berintegritas. Sebagai pelayan yang berintegritas, tidak meniadakan sedikitpun ajaran-ajaran Tuhan yang sudah tercatat di dalam alkitab.

Jadi, pelayan Tuhan harus mampu konsisten dalam pengajaran, tidak meniadakan sedikitpun ajaran-ajaran Tuhan, bahkan jika ada ajaran-ajaran Tuhan yang sudah ditiadakan, diterapkan kembali sehingga dalam pelayanan para pelayan Tuhan nama Tuhan dipermuliakan.

\section{Supaya Pelayan Tuhan Bisa Hidup Benar Di Hadapan Tuhan}

Hidup benar, kudus, suci itu sangat penting untuk diterapkan di dalam setiap kehidupan sebagai umat manusia. Sebagai pelayan Tuhan, perlu dipertanyakan jika masih hidup tidak benar di hadapan Tuhan. Pada zaman PL Tuhan memberikan setiap peraturan, dan ketetapan-Nya kepada bangsa pilihan-Nya, yaitu bangsa Israel, dengan tujuan supaya umat-Nya bisa hidup benar di hadapan Tuhan. Dengan demikan sangat jelas bahwa hidup benar itu, sangat perlu, karena itu adalah salah satu tujuan Allah ketika manusia diciptakan. Ketika manasia sudah hidup benar dihadapan Tuhan, sudah otomatis di dalam diri orang itu sudah mempermuliakan nama Allah lewat pola hidup-nya yang benar di hadapan Tuhan. Sebagai pemimpin terkhusus pemimpin dalam bergereja, yang terutama dilihat oleh banyak orang adalah perbuatan dan karakter setip hari.

Karakter para pelayan Tuhan, dinilai oleh dunia dan oleh mereka yang menimbang apakah teladan mereka pantas diikuti. Paulus menulis kepada Titus, "dan jadikanlah dirimu sendiri suatu teladan dalam berbuat baik. Hendaklah engkau jujur dan bersungguhsungguh dalam pengajaran-mu sehat dan tidak bercela dalam pemberitaanmu sehingga lawan menjadi malu, karena tidak ada hal-hal yang buruk yang dapat mereka sebarkan tentang kita" (Titus 2:7-8). ${ }^{56}$

Sebagai pelayan Tuhan, motivasi adalah kemampuan dalam meyakinkan orangorang untuk melakukan hal-hal yang benar, yaitu kehendak Allah. Berkaitan dengan kepemimpinan rohani adalah motivasi adalah memampukan dalam meyakinkan orang-

\footnotetext{
${ }^{56}$ Mike Shipman, Kepemimpinan Kerasulan..., 80.
} 
orang untuk menyerahkan diri-nya kepada Kritus, untuk dibabtis, dan menaati Amanat Agung, sehingga menghasilkan jemaat-jemaat yang benar-benar takut akan Tuhan. ${ }^{57}$

Hidup benar juga mengatasi kebiasaan-kebiasaan yang berdosa, para pekerja Tuhan harus juga mengatasi kecenderungan untuk bermegah atas diri sendiri. Diperlakukan kerendahan hati dalam melatih orang-orang percaya baru sebagai rekan yang setara. ${ }^{58}$ Allah sangat menginginkan agar setiap orang percaya supaya tetap menjaga kekudusan hidup di hadapan-Nya. Sama halnya ketika Allah berfirman kepada Musa untuk mengatakan kepada umat Israel, "kuduslah kamu, sebab Aku, Tuhan, Allah-mu, kudus" (Im. 19:2). Yesus memerintahkan murid-murid-Nya untuk menjadi "sempurna sama seperti Bapa-mu yang dis Surga adalah sempurna" (Mat. 5:44). Kata yang diterjemahkan menjadi "sempurna" diartiak "utuh" atau "lengkap". Rasul Petrus mendorong setiap orang percaya supaya: "bertumbuhlah dalam kasih karunia dan pengenalan akan Tuhan dan juruselamat kita" (2 Pet. 3:18). Untuk mengikuti arahan Musa, printah Kristus, dan dorongan Petrus, pelayan harus tetap menjadi murid sejati Yesus Kristus, pembelajaran Firman Allah, dan praktis disiplin kehidupan kristiani. ${ }^{59}$ Jadi, pelayan Tuhan harus mampu hidup benar di hadapan Tuhan, sehingga bisa menjadi teladan kepada banyak orang, terkhusus kepada jemaat yang sedang dilayani, dan nama Tuhan yang dipermuliakan.

\section{Pelayan Tuhan, Memiliki Pola Hidup Yang Jujur}

Sebagai peelayan Tuhan yang berintegritas harus memilik pola hidup yang jujur. Ada peribahasa yang mengatakan bahawa 'kejujuran adalah mata uang yang berlaku dimana-mana'. Orang jujur dimanapun ia berada akan disenangi oleh banyak orang. Pribadi yang jujur, artinya tidak berbohong, tidak memutar balikan keadaan. Artinya bahwa orang yang jujur tidak merubah keadaan, misalnya dari yang salah, menjadi benar, dari yang benar, menjadi salah. Sebagai pelayan Tuhan hal ini sangat tidak diperbolehkan, tetapi yang diingikan Tuhan adalah berkata seadanya, tanpa ada yang ditambah dan dikurangi. Pemimpin yang jujur sangat bersangkuatan dengan etika.

Motivasi dasar seseorang akan sangat menentukan sikap/perilaku orang tesebut, baik terhadap orang lain maupun dalam pekerjaan. Seorang pemimpin Kristen perlu memastikan apakah ia memiliki motivasi yang sesuai dengan firman Allah. Karena itu ia perlu mengevaluasi motivasi serta orientasi yang ada padanya dengan sikap terbuka. ${ }^{60}$ Kejujuran dalam alkitab adalah tidak berdusta. Paulus menulis tentang komitmennya untuk

\footnotetext{
${ }^{57}$ Ibid., 87.

58 Ibid., 82.

${ }^{59}$ Joe E Trul, Etika Pelayanan Gereja..., 89.

${ }^{60}$ Ibid., 57.
} 
mengurus dengan cara jujur uang yang diberikan orang-orang percaya untuk suatu dana bantuan bagi orang-orang yang kekurangan, dia berkata, "karena kami memikirkan yang baik, bukan hanya di hadapan Tuhan, tetapi juga di hadapan Manusia” (2 Kor. 8:21). Kejujuran melibatkan cara hidup yang benar dan pola pemikiran yang patut dipuji dan dihormati. $^{61}$

Kejujuran ini sangat besar dampaknya, bisa berdampak kepada orang lain, bisa merugikan pihak lain, misalnya ketika Iblis mencobai Adam dan Hawa di Taman Eden ketika ia membujuk dengan berbagai cara, salah satu caranya adalah memutar balikkan kebenaran yang disampaikan Tuhan Kepada Adam dan Hawa, Iblis berdusta, tidak jujur. Kejatuhan Adam dan Hawa di Taman Eden adalah akibat dusta yang dilakukan Iblis terhadap mereka. Iblis menghampiri manusia dengan bersikap modus operandi yang sama.

Suatu gaya hidup yang jujur berkembang dari usaha yang rajin dan doa. Kejujuran harus meliputi cara hidup seluruhnya maupun perincian yang tertentu dalam kebenaran. Karena itu mungkin bagi seorang untuk menjadi jujur secara saksama dalam satu bidang kehidupannya dan tidak jujur secara keji dalam bidang yang lain. Apabila sudah jujur berarti mengatakan yang benar. ${ }^{62}$ Pengguna yang paling umum dari kata kebenaran adalah sebagai kenyatan-kenyataan. Menyajikan kenyataan-kenyataan yang benar adalah lawan dari berdusta. Paulus berkata: "Aku mengatakan kebenaran dalam Kristus, aku tidak berdusta, suara hati-ku turut bersaksi dalam Roh Kudus" (Rm. 9:1). ${ }^{63}$

Oleh sebab itu, dalam pelayanan bergereja sebagai pelayan Tuhan harus memiliki pola hidup yang jujur, atau tidak diperbolehkan untuk menjadi saksi dusta, karena itu adalah salah satu perintah Tuhan yang diterima oleh Musa di Gunung Sinai. Tentunya jika melanggar perintah itu, maka Allah akan memberikan teguran kepada orang yang melanggar perintah tersebut, dan bukan hanya itu saja, dampak dari ketidak jujuran, atau menjadi saksi dusta bisa berdampak nagatif kepada pihak lain seperti yang terjadi kepada Adam dan Hawa. Pola hidup yang jujur itu pada dasarnya salah satu pilar yang dianggap utama. Oleh sebab itu pola hidup yang jujur sangat penting, terlebih dalam status sabagai pelayan Tuhan.

\section{Pelayan Tuhan Mampu Mengasihi Musuh}

Hal yang sangat sulit untuk dilakukan oleh setiap manusia, adalah mengasihi musuh. Berbicara mengasihi musuh tentunya menyangkut pola hidup damai terhadap

\footnotetext{
${ }^{61}$ Jerry White, Kejujuran Moral dan Hati Nurani..., 36.

62 Ibid., 37.

${ }^{63}$ Ibid., 38.
} 
seteru. Berdamai terhadap musuh, itu juga susah, apalagi untuk mengasihi musuh. Dalam pandangan dunia mengatakan bahwa orang yang memusuhi kita, harus hati-hati untuk menghadapinya, apalagi untuk mengasihinya. Tetapi kali ini berbeda dengan ajaran Tuhan Yesus. Ajaran Tuhan Yesus mengatakan bahwa setiap orang yang menyakiti hati kita, harus tetap mengasihinya. Yesus memberikan suatu perintah bahwa apabila ada orang yang menyakiti hati kita, memusuhi kita seharusnya yang kita lakukan adalah mengasihi dengan cara mendoakannya. Penulis Amsal berkata: "Jikalau seterumu lapar, berilah dia makan roti, dan jikalau dahaga berilah dia minum air. Dalam hal mengasih perlu sikap yang sabar, sehinga dengan ada kesabaran maka amarah tidak terjadi, tetapi selalu untuk mengasihi.

Pertumbuhan karakter pemimpin Kristen harus dimulai dari "bertumbuh dalam kasih" (Yoh. 13:34-35). Pertumbuhan di dalam kasih ditandai oleh sikap dan upaya yang ajeg, yang mengusahakan kebaikan tertinggi bagi sesama/ orang yang dipimpin. Pemimpin yang bertumbuh dalam kasih akan tetap dan terus berusaha mengasihi dalam segala kondisi/situasi, sehingga orang yang dipimpinnya merasa dipedulikan dan aman dibawah kepemimpinannya. ${ }^{64}$

Tentunya dalam artian ini tertuju bagaimana cara mengasihi musuh, dengan cara ada tindakan bukan hanya dalam perkataan saja. Alasan mengapa harus yang memusuhi kita yang kita kasihi karena Tuhan Yesus mengatakan, kalau kita mengasihi orang yang baik kepada kita, orang berdosa pun dapat melakukan itu. Sebagai orang yang pasti masuk surga karena kita percaya Tuhan Yesus, maka kita bukan hanya mengasihi orang yang baik kepada kita, tetapi juga orang yang berbuat jahat kepada kita. Mengasihi orang jahat tidak mudah, tetapi ini adalah perintah Tuhan. Injil Markus 12:30-34, Tuhan Yesus mengatakan bahwa mengasihi Tuhan dan manusia adalah lebih utama daripada memberikan persembahan. Sekalipun kita bisa kasih persembahan besar di Gereja, tetapi kalau tidak bisa mengasihi orang yang berbuat jahat, maka sia-sia semua persembahan yang diberikan kepada Tuhan. Surat 1 Korintus 13 mengatakan bahwa jika kita memberikan segala sesuatu kepada Tuhan dan manusia, jika kita tidak mempunyai kasih, sia-sia semua pemberian kita. Sekalipun kita punya iman yang luar biasa, tetapi jika tidak mempunyai kasih, sia-sialah semuanya. Kasih kita kepada Tuhan dan manusia, akan menjadi sempurna, kalau kita bisa mengasihi orang yang berbuat jahat kepada kita.

\footnotetext{
${ }^{64}$ Yakub Tomatala, Kepemimpinan Yang Dinamis..., 52.
} 
Alkitab memang merupakan sumber cara hdup yang baik dan benar yang kaya yang bisa ditimba oleh pelayanan, yang berterus terang memberitakan perkataan kebenaran. Alkitab adalah sumber rujukan utama tindakan etis. Mengetahui kehendak Allah dan menggali perbuatan baik tidak selalu mudah, berbuat kehendak Tuhan sulit untuk melakukannya. Misalnya, mengasihi musuh, bertentangan dengan keinginan manusia. ${ }^{65}$ Jadi, pelayan Tuhan harus mampu mengasihi orang yang berbuat jahat, sehingga akhirnya para pelayan Tuhan hidup dalam kasih, sama seperti kasih Yesus terhadap semua orang, terkhusu kepada orang yang percaya.

\section{PENUTUP}

Menjadi seorang pelayan Tuhan yang sangat penting adalah harus memiliki integritas. Berbicara mengenai integritas tentunya banyak sekali cakupannya. Dalam hal ini, sesuai dengan pembahasan penulis pada bab sebelumnya, maka penulis mencantumkan hanya empat poin yang bersangkutan dengan pelayan Tuhan yang berintegritas, bahkan yang Tuhan Yesus sendiri ajarkan kepada banyak orang, dan juga kepada para muridmurid-Nya ketika Ia khotbah di Bukit, yaitu sebagai pelayan Tuhan yang berintegritas adalah tidak boleh meniadakan ajaran-ajaran Tuhan. Sebaliknya jika ada ajaran-ajaran Tuhan yang sudah ditiadakan, diterapkan kembali.

Hal kedua adalah yang dimiliki oleh seorang pelayan Tuhan adalah harus menjaga kesucian hidup atau hidup benar di hadapan Tuhan. Ini juga sangat penting, menjaga kesucian hidup atau hidup benar di hadapan Tuhan, yaitu mampu menyenangkan hati Tuhan baik dalam perkataan, maupun dalam tindakan. Hal ini menekankan bahwa apapun yang dilakukan dan yang dikatakan harus motivasinya hanya untuk kemuliaan nama Tuhan, bukan untuk mencari nama, dan bukan untuk sesama manusia. Hal yang ketiga adalah jujur atau tidak bersumpah palsu. Kejujuran berbicara mengenai moral yang baik seseorang dalam menjalankan tugas apapun. Ketika seseorang sudah jujur, maka seseorang itu sudah otomatis tidak perlu bersumpah karena apa yang dia katakana sudah sejujurjujurnya. Pemimpin yang jujur sangat disenangi banyak orang.

Hal yang keempat adalah hidup dengan penuh kasih. Sebagai pelayan Tuhan harus memiliki pola hidup yang penuh kasih. Pelayan Tuhan yang tidak memiliki kasih tidak ada

\footnotetext{
${ }^{65}$ Joe E. Trull, Etika Pelayanan..., 53.
} 
faedahnya. Paulus berkata bahwa orang yang tidak memiliki kasih, sama halnya dengan gong yang gemerincing yang berkumandang yang tidak ada gunanya, tetapi kasih lebih berfaedah dari semuanya. Kasih dalam hal ini bukan hanya tertuju kepada orang-orang yang mengasihi kita, tetapi kasih dalam artian ini kasih yang dilakukan kepada seteru. Artinya bahwa dalam mengasihi, bukan hanya orang yang mengasihi kita yang kita kasihi, tetapi orang yang memusuhi kita sekalipun harus kita kasihi. Ketika keempat poin itu dijalankan dalam sebuah pelayanan, maka pelayanan itu akan betumbuh sesuai dengan kehendak Tuhan.

Jadi, integritas pelayan Tuhan yaitu, tidak meniadakan perintah Tuhan, hidup benar di hadapan Tuhan, tidak bersumpah palsu, dan mengasihi musuh hendaknya menjadi sifat dan karakter pelayan Tuhan dalam menjalankan tugas dan panggilan pelayanan, serta mampu memahami tentang integritas dengan benar dan alkitabiah, sehingga pelayanan yang akan dikerjakan semakin bertumbuh, dan nama Tuhan yang dimuliakan, dan ditinggikan. 


\section{DAFTAR PUSTAKA}

Abineno, J. 1. Ch. (2009). Khotbah Di Bukit Catatan-Catatan Matius 5-7, Jakarta: BPK Gunung Mulia

Aland, Kurt. (1985). Synopsis of The Four Gospels, America: United Bible Societies.

Barclay, William. (2003). Pemahaman Alkitab Setiap Hari, Jakarta: BPK Gunung Mulia.

Bell, Albert A. (1998). Exploring The New Tetament World, Nashville: Thomas Nelson Publishers.

Bibleworks 7, CD-ROM.

Brownlee, Malcolm. (2011). Pengambilan Keputusan Etis dan Faktor-Faktor Di Dalam.

Champan, Adima. (2014). Pengantar Perjanjian Baru, Bandung: Sahabat Kalam Hidup II

Drescher, John M. (2009). Melakukan Buah Roh, Jakarta: BPK. Gunung Mulia.

Edwin, Mustafa, dan Hardius. (2008). Proses Penelitian Kuantitatif, Jakarta: Lembaga Penerbit FEUI.

Friberg, Barbara. (1985). Analytical Lexicon of The Greek New Testament, Nashvile: Nelson.

Hakh, Samuel Benyamin. (2010). Perjanjian Baru, Bandung: Bina Media Informasi.

Haryono, Daniel. (2012). Kamus Besar Bahasa Indonesi Edisi Baru, Jakarta: Muliapurna Jayaterbit.

Heer, J. J. de. (2003). Tafsiran Alkitab Injil Matius, Jakarta: BPK Gunung Mulia.

Herwinesastra. (...). Pengaruh Kepemimpinan Kristen Di Era Globalisasi Abad.

Hester, H. I. (2001). The Heart of The New Testament, Nashville, Tennesse: Bradmen Press.

James. (1901). Strongs Exhaustive Concordance of the Bible, American: World Bible Publishers.

Leks, Stefan. (2007). Tafsiran Injil Matius, Jakarta: Anggota IKAPI.

Louw, Jhanes E. (1989) Greek-English Lexicon of The New Testament, New York: United Bible Societies.

Lubis, Mochtar. Manusia Indnesia, Jakarta: Yayasan Idayu.

Metzger, Will. (2013). Beritakanlah Kebenaran, Surabaya: Momentum.

Moulton, Harord K. (1977). The Analytical Greek Lexicon Revised, America: The Zondervan Corporation. 
Ningrat, Kuncoro. (1977). Methodologi Penelitian Masyarakat, Jakarta: Gramedia.

Rosin, H. (2003). Tafsiran Kitab Keluaran, Jakarta: BPK Gunung Mulia.

Sabda 4, CD-ROM.

Scoot, Robert. (1858). Greek-English Lexicon, Leipzig.

Shipman, Mike. (2017). Kepemimpinan Kerasulan, Bandung: Penerbit Dian Cipta.

Simanjuntak, A. (2005). Tafsiran Alkitab Masa Kini 3, Jakarta: BPK. Gunung Mulia.

Strong, James. (1901). Strongs Exhaustive Concordance of the Bible, American: World Bible Publishers.

Subana, M. dan Suderajat, Dasar-dasar Penelitian Ilmiah, Bandung: Pustaka Setia.

Sugono, Dendy. (2011). Kamus Besar Bahasa Indonesi Pusat Bahasa, Jakarta: Gramedia Pustaka Utama.

Sutanto, Hasan. (2004). Perjanjian Baru Interlinear Yunani Indonesia dan Konkordansi Perjanjian Baru, Jakarta: Lembaga Alkitab Indonesia.

Tong, Caleb. (1998). Kepemimpinan dan Pembinaan Warga Gereja, Jakarta: Sinar Harapan.

Tulluan, Ola. (1999). Introduksi Perjanjian Baru, Malang: YPPII.

White, Jerry. (...). Kejujuran Moral dan Hati Nurani.

Yosafat. (2013). Integritas Pemimpin Pastoral: Menjadi Pemimpin Yang Memadukan Kata-Perbuatan, Iman-Ilmu, Teori-Praktik, Jabatan-Integritas, Yogyakarta. 